\title{
VI
}

\section{QUESTÃO URBANA E SEGURANÇA PÚBLICA NA FAVELA DA MARÉ*}

\author{
Eblin Farage \\ Francine Helfreich \\ Camila Barros \\ Miriam Krenæinger
}

\section{Introdução}

Este capítulo versa sobre o debate da questão urbana, com ênfase na forma como a violência estatal se manifesta sobre a população moradora das favelas, a partir do estudo sobre a realidade do conjunto de favelas da Maré, uma das maiores favelas do Brasil, situado no Rio de Janeiro.

Partiremos do pressuposto de que as favelas se constituem como espaços de moradia de segmentos da classe trabalhadora que historicamente foram lateralizadas pelo Estado no que se refere às políticas públicas de qualidade. Ao contrário da tese que defende sua ausência, consideramos que o Estado sempre esteve presente nesses territórios através da segurança pública via ações repressoras, violentas ou com políticas sociais insuficientes e ineficazes. Uma política pobre e subalternizada para uma população empobrecida.

Para tanto, o estudo deste território, como uma expressão da questão social, ${ }^{1}$ explicita os dilemas e contradições da questão urbana da cidade do Rio de Janeiro, considerada uma das cidades que exemplifica o desenvolvimento desigual dos territórios.

O ponto de partida deste estudo se dá à luz da tese do desenvolvimento desigual e combinado do capitalismo - estudada por diferentes autores que

\footnotetext{
* DOI - 10.29388/978-65-86678-40-6-0-f.167-192

1“'Como mais do que as expressões da pobreza, miséria e 'exclusão'. Ela condensa a banalização do humano, que atesta a radicalidade da alienação e a invisibilidade do trabalho social - e dos sujeitos que o realizam - na era do capital fetiche" (IAMAMOTO, 2007, p. 125), e nesse sentido também representa a organização e a resistência de amplos segmentos da classe trabalhadora, ou seja, desigualdade e luta.
} 
nos ajudam a compreender a forma como o espaço urbano é constituído. Este texto nos desafia a pensar o conjunto de favelas da Maré como parte da cidade, tendo no Estado um dos principais agentes conformadores e violadores de direitos.

Os dados recentes da segurança pública e da ação do Estado na Maré explicitam a perspectiva estruturante de uma cidade que é produzida desigualmente e que assim se mantém pela ação política direcionada, que encontra assento nas políticas públicas de baixa qualidade e na perspectiva de controle da população moradora via consenso e coerção, nos termos de Gramsci (2000).

O levantamento que apresentamos parte da experiência de estudo, pesquisa e trabalho na área da questão urbana e segurança pública, tendo como foco o território da Maré, que revela, entre outras coisas, a necropolítica aplicada pelo Estado.

\section{A Maré como expressão da questão urbana carioca}

O desenvolvimento das cidades modernas segue um fio condutor de estruturação a partir do binômio industrialização/urbanização, tendo como eixo o processo de desenvolvimento desigual e combinado do capitalismo, conforme trabalhado por Trotsky (2007) e Lenin (2005). Nesse processo, marcado pelas necessidades do desenvolvimento capitalista, a cidade vai sendo formada por distintos territórios, marcados pelo desigual investimento estatal. Mas, além do Estado, outros agentes sociais interferem na construção dos espaços, a partir da intervenção em seu cotidiano. Cotidiano compreendido como o espaço de produção real da vida, da reprodução da ideologia, da construção das relações sociais de existência, considerando diferentes aspectos da vida, como a família, a escola, a religião, o trabalho, a cultura e as formas de organização coletivas. Nessa perspectiva, o desenvolvimento das ações públicas e os equipamentos do Estado são interlocutores essenciais para o processo de produção e reprodução social da vida. Assim, igrejas, grupos criminosos armados, movimentos sociais, organizações não governamentais, centros sociais, equipamentos públicos, vão sendo construídos pelas forças em disputa na sociedade.

Lefebvre (2008) defende a tese de que o processo de industrialização que gerou a urbanização, e que por tempos foi priorizada como a questão central no debate sociológico sobre a cidade, se desloca na contemporaneidade para a problemática urbana. Segundo o autor, a urbanização rapidamente se tor- 
na um problema maior do que a própria industrialização, trazendo contradições e consequências para a sociabilidade, já que se constitui ainda como um processo não acabado. Refletindo sobre a cidade, ${ }^{2}$ Lefebvre (2008, p. 82) define-a como um conjunto de conceitos, no qual destaca:

a) A cidade é um objeto espacial ocupando um sítio e uma situação que é preciso estudar, enquanto objeto, com diferentes técnicas e métodos $[\ldots]$;

b) Nesse sentido, a cidade é uma mediação entre uma ordem próxima e uma ordem distante. A ordem próxima é aquela do campo circundante que a cidade domina, organiza e explora, extorquindo-lhe sobretrabalho $[\ldots]$;

c) A cidade é uma obra no sentido de uma obra de arte. O espaço não é apenas organizado e instituído. Ele também é modelado e apropriado por este ou aquele grupo, segundo suas exigências, sua ética e sua estética, ou seja, sua ideologia $[\ldots]$

Nessa perspectiva, o conjunto de favelas da Maré, marcado por intervenções estatais e forte organização dos moradores, se constitui como uma expressão do processo de conformação desigual do espaço urbano, delimitado pela própria conformação da cidade do Rio de Janeiro a partir de seus traços históricos, políticos, culturais, sociais e econômicos.

\section{O desenvolvimento desigual e combinado e a Questão Urbana}

O desenvolvimento econômico na América Latina e no Brasil foi marcado pelo que Fernandes (1981), Harvey (2004), Ianni (2004) e outros chamam de desenvolvimento capitalista desigual e combinado. Desenvolvimento desi-

2 Para Lefebvre (2008, p. 84) “[...] o urbano se distingue da cidade precisamente porque ele aparece e se manifesta no curso da explosão da cidade, mas ele permite reconsiderar e mesmo compreender certos aspectos dela que passaram despercebidos durante muito tempo: a centralidade, o espaço como lugar de encontro, a monumentalidade etc. O urbano, isto é, a sociedade urbana, ainda não existe e, contudo, existe virtualmente; através das contradições entre o habitat, as segregações e a centralidade urbana que é essencial à prática social, manifesta-se uma contradição plena de sentido". 
gual e combinado porque integra, ao mesmo tempo, o avanço e a modernização provocada pela expansão capitalista em suas diferentes fases, especificamente em sua fase monopolista industrial, com elementos sociais arcaicos e conservadores.

$\mathrm{Na}$ combinação entre o moderno e o arcaico, entre o desenvolvido e o pré-desenvolvido, são criadas marcas internas e externas aos países, com desdobramentos na conformação urbana. A vida social se organiza a partir do processo combinado entre polos desenvolvidos e polos em desenvolvimento, em um movimento de inter-relação e dependência mútua no qual a riqueza e o desenvolvimento dos países centrais se dão a partir da exploração e da geração de riqueza dos e nos países periféricos.

O processo de desenvolvimento desigual e combinado tem sua origem, no processo de colonização, já na primeira fase da globalização, ${ }^{3}$ como caracterizada por Santos (2008), ao se referir à expansão marítima do século XVI. Compreende-se que o capitalismo, como um processo mundial de consolidação de relações sociais, constrói formas necessárias à sua expansão. Nesse sentido, a universalização do mundo começa no período da expansão comercial ou mercantil, se desenvolve, potencializa e amadurece ao longo das fases do desenvolvimento capitalista, até chegar ao final do século XX com a globalização tecnológica articulada ao desenvolvimento do neoliberalismo. ${ }^{4}$

No período da colonização, os territórios ${ }^{5}$ são organizados de forma distinta, sem rigor na forma e na organização social, marcando o surgimento das primeiras cidades brasileiras. Presidido inicialmente pelo desenvolvimento

3 Para Santos (2008, p. 23), a “[...] globalização é, de certa forma, o ápice do processo de internacionalização do mundo capitalista. Para entendê-la, como, de resto, a qualquer fase da história, há dois elementos fundamentais a levar em conta: o estado das técnicas e o estado da política". Segundo o autor, os elementos que permitem compreender o processo de globalização em curso são "[...] a unicidade da técnica, a convergência dos momentos, a cognoscibilidade do planeta e a existência de um motor único na história, representada pela mais-valia globalizada. Um mercado global utilizando esses sistemas de técnicas avançadas resulta nessa globalização perversa" (SANTOS, 2008, p. 24). Para ver mais sobre o assunto: Harvey (2004), Santos (2008), Netto e Braz (2006).

4 Segundo Harvey (2008, p. 12), “[...] o neoliberalismo é em primeiro lugar uma teoria das práticas político-econômicas que propõe que o bem-estar humano pode ser melhor promovido liberando-se as liberdades e capacidades empreendedoras individuais no âmbito de uma estrutura institucional caracterizada por sólidos direitos à propriedade privada, livres mercados e livre comércio". Para ver mais sobre neoliberalismo: Netto e Braz (2006) e Anderson (1995).

5 Segundo Haesbaert (2007, p. 45), “[...] um marxista, dentro do materialismo histórico e dialético, irá defender uma noção de território que: i) privilegia sua dimensão material, sobretudo no sentido econômico, ii) está historicamente situada e iii) define-se a partir das relações sociais nas quais se encontra inserido, ou seja, tem um sentido claramente relacional". 
do comércio, e mais tarde pelo desenvolvimento industrial, é apenas no século XX que as cidades começam a se consolidar. Segundo Maricato (2008), é o advento do trabalhador livre, da industrialização e da República que impulsionam a organização das cidades.

As reformas urbanas, realizadas em diversas cidades brasileiras entre o final do século XIX e início do século XX, lançaram as bases de um urbanismo moderno "à moda" das periferias. Realizavam-se obras de saneamento básico para eliminação das epidemias, ao mesmo tempo em que se promovia o embelezamento paisagístico e eram implantadas as bases legais para um mercado imobiliário de corte capitalista. A população excluída desse processo era expulsa para os morros e franjas da cidade. Manaus, Belém, Porto Alegre, Curitiba, Santos, Recife, São Paulo e especialmente o Rio de Janeiro são cidades que passaram por mudanças que conjugaram saneamento ambiental, embelezamento e segregação territorial, nesse período (MARICATO, 2008, p. 17).

As cidades, como fruto do processo de desenvolvimento, acabam por ser a expressão mais tangível do espaço urbano, tornando-se, em alguns momentos, sinônimo do urbano. Porém, vale destacar que a cidade, apesar de ser o símbolo do processo de urbanização, não representa de forma autônoma e independente o espaço urbano. A cidade, ao se constituir de distintos territórios, passa a evidenciar a conformação desigual do espaço urbano, que se expressa não na geografia natural dos territórios, mas em suas intervenções sociais e urbanísticas.

O espaço urbano, definido por Corrêa (1995, p. 10), como o “[...] conjunto de diferentes usos da terra justapostos entre si”, revela a apropriação desigual do solo, que se torna uma importante mercadoria na sociedade capitalista contemporânea, e a distribuição desigual da riqueza socialmente produzida, traduzida não apenas pelas construções imobiliárias, mas também pela distribuição dos equipamentos públicos e privados.

A desigualdade gerada na apropriação e ocupação do solo urbano conforma distintos territórios na cidade, em especial a partir do processo de industrialização, e se torna um marco no desenvolvimento da cidade. Os países, outrora agrários e escravocratas, pouco a pouco passam a se tornar urbanos e industriais, gerando a necessidade de distintas adaptações e transformações.

As cidades se alteram a partir da conformação de novas relações sociais que deixam de se basear na produção agrícola e passam a ter, como foco central 
da produção da riqueza, a indústria. Essas relações dispõem de um novo tônus propulsor e impõem uma nova configuração na apropriação do espaço, incluindo desde o redimensionamento do local de moradia dos trabalhadores e dos donos dos meios de produção, até a constituição viária, a colocação de equipamentos públicos, etc.

As grandes cidades brasileiras passaram por esse processo, de forma emblemática a partir do final do século XIX, intensificado a partir do século XX. Segundo Corrêa (1995), as cidades passaram a ser divididas em: área central, área de lazer, área cultural, etc.

Eis o que é espaço urbano: fragmentado e articulado, reflexo e condicionante social, um conjunto de símbolos e campo de lutas. É assim a própria sociedade em uma de suas dimensões, aquela mais aparente, materializada nas formas espaciais (CORRÊEA, 1995, p. 9).

O desenvolvimento da malha urbana carioca acontece no mesmo sentido que o da maior parte das cidades brasileiras. Inicia sua expansão a partir da proximidade com os núcleos centrais, que se formam para acessar os bens produzidos, facilitar a troca e a circulação. Nesse sentido, conforme expressa Corrêa (1995), o centro das cidades se forja a partir do desenvolvimento do comércio, da indústria, do transporte e da infraestrutura social, cultural, etc. Constituindo-se a partir de uma necessidade em comum, o acesso a serviços, bens e mercadorias, a cidade se desenvolve de forma extremamente desigual, em especial nos países periféricos. Desigualdade marcada pela diferença entre cidades de países distintos, entre cidades do mesmo país e entre territórios de uma mesma cidade. Como afirma Corrêa (1995, p. 7), “[...] é simultaneamente fragmentado e articulado: cada uma de suas partes mantém relações espaciais com as demais, ainda que de intensidade muito variável".

A variedade na constituição das cidades e do espaço urbano deriva, entre outros fatores, dos seguintes elementos:

- Desenvolvimento dependente dos países periféricos;

- Ação do Estado na conformação do espaço que coadune com os interesses sociais e econômicos das classes economicamente dominantes;

- Fragmentação dos territórios que constituem a mesma cidade, a partir da constituição dos locais de moradia de segmentos da burguesia e de segmentos da classe trabalhadora; 
- Distribuição desigual de equipamentos públicos, áreas de lazer, vias viárias, espaços culturais, etc.

Nesse sentido, o espaço urbano se constitui como produto das ações presentes do Estado e da iniciativa privada, mas também como produto de ações passadas que deixam marcas em sua constituição. A cidade, além de produto do desenvolvimento desigual e combinado do capital, também passa a ser produtora de sentidos, desejos, valores e identidades junto aos moradores dos distintos territórios.

Os territórios são espaços nos quais se desdobram as relações sociais, a partir da construção da vida cotidiana. Nesse sentido, Lefebvre (2008) e Santos (2008) afirmam que o espaço é construído, não nasce pronto, acabado. E como afirma Harvey (2004), não pode ser definido apenas pelas dimensões geográficas. Coloca-se como desafio a compreensão das distintas dimensões que conformam as relações sociais produtoras de sentidos, identidades e relações que produzem os sujeitos sociais nos territórios. Sujeitos materializados em classes sociais, mesmo que não desenvolvam tal consciência, limitando-se a uma posição superficial de compreensão e posicionamento na sociedade.

Os territórios se constituem a partir da dinâmica econômica e também a partir da identidade de seus moradores. Em um movimento dialético, os territórios são construídos pelos sujeitos reais que aí se fixam, com suas identidades, valores, perspectivas. Ao mesmo tempo em que se organizam enquanto espaço, produzem novas identidades ${ }^{6}$ e subjetividades. Nessa perspectiva, a cidade não é e nem está estática; ao contrário, está em constante processo de mutação, na medida em que é produto e produtora de identidades, subjetividades e sentidos para a vida urbana.

Segundo Santos (2007, p. 13), “[...] o território é o lugar em que desembocam todas as ações, todas as paixões, todos os poderes, todas as forças, todas as fraquezas, isto é, onde a história do homem plenamente se realiza a partir das manifestações da sua existência". Nesse sentido, os territórios da cidade são também fruto das disputas e das contradições próprias das relações sociais, como espaços que corporificam a existência dos sujeitos, o que nos explicita a experiência no Rio de Janeiro.

6 O conceito de identidade vem sendo discutido desde a antiguidade, não tendo apenas uma definição, já que cada área de conhecimento a define a partir de determinados parâmetros. Neste trabalho a identidade é considerada como o conjunto de características presentes nas relações sociais de um determinado grupo considerando aspectos sociais, econômicos, culturais e territoriais que forjam sua cotidianidade. 


\section{O Rio de Janeiro e a constituição do espaço das Favelas}

A experiência carioca quanto à gênese e o desenvolvimento das favelas, assim como nas demais cidades brasileiras, expressa um processo de modernização baseado na segregação e na fragmentação do espaço urbano. As favelas cariocas surgem no início do século passado, paralelamente ao processo de industrialização e urbanização do Brasil, diretamente articuladas às particularidades da formação social brasileira, que tem nas suas raízes escravocratas a sua maior expressão. Nesse sentido, as origens das favelas cariocas também carregam a marca de um processo onde a população, sobretudo negra, sem trabalho, sem terra, sem teto, sem emprego e moradia, busca espaços para garantir a produção social da vida.

As principais produções teóricas mostram que o processo migratório campo-cidade ocorrido no Brasil no final dos anos de 1930 e início dos anos de 1940 também influenciaram a demanda por habitação. Com isso, encostas dos morros e cortiços foram se constituindo como lugar possível de moradia desse segmento populacional que demandava um lugar para viver.

No Rio de Janeiro, o "Morro da Providência" é considerado por alguns estudiosos como o local que, no final do século XIX, marcou as origens da favela. Nos estudos de Valladares (2005), os soldados que retornavam da Guerra de Canudos $^{7}$ se instalaram naquele espaço, construindo suas casas e buscando pressionar o Ministério da Guerra a lhes pagar os soldos devidos. Daí, temos a rápida associação entre morro e favela em face dessa forma de ocupação do espaço urbano e do binômio morro/asfalto que futuramente agregaria uma lógica estereotipada de favela versus cidade formal.

O Morro da Providência passou a ser conhecido como "Morro da Favella" entrando na literatura e nas ciências sociais como a primeira favella do Rio de Janeiro. A esse processo, Valladares (2005) denomina por um "mito de origem", a visão de Euclides da Cunha do arraial de Canudos em sua obra "Os sertões" expressar o período em que a favela carioca é "descoberta". No entanto, na época, o foco principal dos higienistas era o "cortiço". Essas moradias

\footnotetext{
${ }^{7}$ A Guerra de Canudos, que aconteceu no período de 1896 a 1897, foi um conflito militar entre os moradores do Arraial de Canudos, liderados por Antônio Conselheiro e o governo do estado da Bahia, pelo fato dos primeiros se recusarem a pagar impostos e seguir as diretrizes do governo. O conflito chegou ao fim na terceira tentativa de ataque das forças armadas do estado, reforçadas por militares enviados pelo governo federal. A Guerra de Canudos, segundo o autor, significou a resistência das populações marginalizadas do sertão nordestino às injustiças sociais da época (MONIZ, 1987).
} 
coletivas, onde viviam as pessoas com menor poder aquisitivo, foram consideradas pelos médicos como um grande perigo para a cidade devido à aglomeração excessiva de pessoas em pequenos dormitórios, à falta de higiene e, por conseguinte, à proliferação de doenças. Segundo Valladares (2005, p. 24),

\begin{abstract}
Definido como um verdadeiro "inferno social", o cortiço carioca era visto como antro da vagabundagem e do crime, além de lugar propício às epidemias, constituindo ameaça à ordem social e moral. Percebido como espaço propagador da doença e do vício, era denunciado e condenado através do discurso médico e higienista, levando à adoção de medidas administrativas pelos governos da cidade.
\end{abstract}

Desde o início do século, os cortiços e sua demolição aparecem na cena política como questão importante, que pressiona os governos. Com a impossibilidade de desenvolvimento dos cortiços na área central da cidade, a autoconstrução de moradias precárias nas encostas e a ampliação de moradias nos subúrbios e periferias da cidade ocorrem de forma mais intensa onde o controle do poder público era menor.

Segundo Campos (2004), em 1821 a população negra constituía quase $60 \%$ da população total da cidade do Rio de Janeiro, sendo que cerca de um quarto dessa era formada por negros alforriados. Em sua pesquisa, o autor mostra a existência da relação entre o quilombo e a favela. Destaca, também, como essa relação é parte intrínseca de um vínculo étnico e geográfico-político, visto que ambos teriam sido construídos como "espaços criminalizados" e que foram gradativamente ocupados por pessoas oriundas do processo de escravidão que, à época, compunham a força de trabalho livre.

Com a expansão da industrialização, as favelas se constituíam como um "problema urbanístico e social", que desafiava a administração pública logo nas primeiras décadas do século XX. Nessa conjuntura, onde as alterações políticas e econômicas impulsionaram os processos migratórios do campo para a cidade, as favelas passam a ser incluídas nos planos de intervenção do poder público. Assim, progressivamente, a questão das favelas ganha atenção das autoridades já que o processo de urbanização e crescimento populacional da cidade se adensava na medida que o processo de industrialização avançava. Nesse sentido, o crescimento populacional, a dificuldade de encontrar habitações baratas, o parco investimento em políticas habitacionais, impulsionam a formação de loteamentos e assentamentos irregulares, que acabam se constituindo em favelas de 
forma muito rápida. A impossibilidade do mercado imobiliário formal de atender às demandas de grande parte da classe trabalhadora, expressa a falácia do modelo neoliberal de autorregulação do mercado. Com isso, "expulsa" para os locais mais longínquos e mais precarizados essa grande parcela da população.

Para Valladares (2005), após o período de "descoberta" da favela, temse um segundo período em que as mesmas irão se constituir como um problema social e urbano, seguido de um terceiro momento, quando a ideia de administrar o problema toma a forma de políticas e ações concretas. Para a autora, um quarto momento inclui a produção de dados oficiais através de censos de favelas e a transformação de um fenômeno local em realidade nacional, a exemplo do Relatório SAGMAS: Aspectos Humanos das Favelas Cariocas, que é uma análise socioeconômica elaborada pela Sociedade de Análises Gráficas e Mecanográficas Aplicadas aos Complexos Sociais (SAGMAS). Esse documento, publicado em 1960, demonstra as ações destinadas ao controle da população pobre, e mostra as primeiras ações das instituições atuantes nas favelas. Até hoje, conforme destacam Valla, Algebaille e Guimarães (2011), esse estudo é considerado por muitos como um dos trabalhos mais exaustivos realizados no Brasil sobre as favelas no Rio de Janeiro.

Conforme Valladares (2005) sintetiza em seus estudos, é possível destacar seis principais fases na relação entre Estado e favelas no Rio de Janeiro, quais sejam:

$1^{\circ}$ ) anos 1930 - início do processo de favelização do Rio de Janeiro e reconhecimento da existência da favela pelo Código de Obras de 1937; $2^{\circ}$ ) anos 1940 - a primeira proposta de intervenção pública correspondente à criação dos parques proletários durante o período Vargas; $3^{\circ}$ ) anos 1950 e início dos anos de 1960 - expansão descontrolada das favelas sob a égide do populismo; $4^{\circ}$ ) de meados dos anos 1960 até o final dos anos de 1970 - eliminação das favelas e sua remoção durante o regime autoritário; $5^{\circ}$ ) anos 1980 - urbanização das favelas pelo BNH (Banco Nacional da Habitação) e pelas agências de serviços públicos após o retorno à democracia; $6^{\circ}$ ) anos 1990 - urbanização das favelas pela política municipal da cidade do Rio de Janeiro, com o Programa Favela/Bairro (VALLADARES, 2005, p. 23)

A essa reflexão, se agrega, na década de 2000, o programa Minha Casa Minha Vida, lançado em 2009 durante o governo de Luiz Inácio Lula da Silva (2003-2006 e 2007-2010) e mantido no governo de Dilma Roussef (2011- 
2014 e 2015-2016), e que se constituiu como um grande programa de moradia popular. Entretanto, o processo retratado acima, junto a outras iniciativas de menor peso, revela a processualidade histórica da construção das favelas cariocas, expressando as contradições típicas da sociedade capitalista. Ao passo que a cidade se desenvolve, se expandem os espaços escassos de políticas e serviços públicos que possibilitam uma vida digna. Em síntese, trata-se de uma escolha pela construção e produção de espaços desiguais que reitera a tese de que o capitalismo não pode se desenvolver sem seus ajustes espaciais, conforme nos apontam os estudos do geógrafo político David Harvey (2004)

Segundo o Harvey (2004), o capitalismo constrói uma geografia marcada pela desigualdade que facilita a acumulação do capital numa dada fase da sua história, o que significa produzir territórios proletarizados, destituídos de bens e serviços de qualidade, em locais onde reside uma parcela significativa da população. Hoje, a cidade do Rio de Janeiro possui 1,4 milhão de pessoas residindo em favelas. Segundo o Censo 2010 do IBGE, considerando apenas a população dessa cidade, cerca de $22,2 \%$ dos cariocas, ou praticamente um em cada cinco, eram moradores de favelas.

A cidade do Rio de Janeiro pode ser considerada uma das cidades mais desiguais do Brasil: um município que convive sem parcimônia com projetos milionários como a Cidade da Música, o Museu do Amanhã e, ao mesmo tempo, a miséria explícita, onde mais de 15 mil pessoas estão em situação de rua, conforme o levantamento mais recente da Defensoria Pública do Estado. ${ }^{8}$ Enfim, por um lado, temos uma população cronicamente lateralizada pelo Estado que destina políticas públicas de baixa qualidade que não respondem às demandas desse segmento e, por outro lado, uma cidade produzida para os ricos.

Trata-se de uma população que se defronta, por sua vez, com bairros que desfrutam de bens e serviços de qualidade, como museus, centros culturais, shoppings, espaços de lazer. E outros em que as ações do Estado se restringem à ação violenta da polícia e/ou frágeis e insuficientes políticas sociais, favorecendo a consolidação do processo de um verdadeiro apartheid social, como é o caso da Maré.

\footnotetext{
8 Para mais informações ver:

$<$ https://g1.globo.com/rj/rio-de-janeiro/noticia/2019/11/21/prefeitura-da-inicio-alevantamento-para-realizar-o-1 censo-da-populacao-em-situacao-de-rua-do-rio.ghtml $>$. Acesso em: 13 jul. 2020.
} 


\section{Algumas considerações sobre o Conjunto de Favelas da Maré}

O Complexo da Maré, considerado um dos maiores e mais populosos espaços populares do Rio de Janeiro, situa-se entre a Avenida Brasil e a Linha Vermelha, à margem da Baía de Guanabara. É mais uma expressão das formas desiguais de apropriação e ocupação da cidade.

O processo de formação do bairro foi consolidado entre os anos 1940 e 2000. Em sua paisagem, insistia, até bem pouco tempo atrás, a presença de palafitas. Isso propiciava um contraste considerável com o entorno, já que o Complexo da Maré está razoavelmente próximo ao Aeroporto Internacional do Galeão e à Universidade Federal do Rio de Janeiro.

A população distribui-se em 2,91 moradores por domicílio em suas 16 comunidades: Marcílio Dias, Praia de Ramos, Roquete Pinto, Parque União, Rubens Vaz, Nova Holanda, Parque Maré, Nova Maré, Baixa do Sapateiro, Morro do Timbó, Bento Ribeiro Dantas, Conjunto Pinheiros, Vila dos Pinheiros, Novo Pinheiros, Vila do João e Conjunto Esperança. Nota-se que no interior de algumas destas comunidades foram constituídos outros espaços, com a chegada de novos moradores e construções de casas, como é o caso de Marcílio Dias, que hoje é subdividido em Kelson e Mandacaru.

O bairro é marcado por um processo desordenado de ocupação e pela rapidez das construções verticais, em sua maioria, destituídas de emboço ou qualquer tipo de acabamento. Há grande circulação de pessoas e veículos, um comércio extremante desenvolvido, com lojas, bares, salões de beleza, além de muitas igrejas. Marcada por um conjunto de características que a diferenciam de outros espaços da cidade, a Maré se destaca pela sua capacidade organizativa, por exemplo, com dois censos populacionais e um Censo de Empreendimentos ${ }^{9}$ realizados por organização local. O primeiro, produzido em 2003, e o outro, mais recente, iniciado em 2012, realizou visitas em 92,01\% dos 47.758 dos domicílios do conjunto de favelas. Nesse censo foi possível afirmar a existência de 139.073 habitantes, sendo considerado o $9^{\circ}$ bairro mais populoso da cidade.

Considerado como um espaço marcado pela violência e destituído de condições dignas de vida, segundo o Censo Maré (2013), há diferentes perfis na identificação étnico-racial dos moradores, onde 62,1\% se declararam como pre-

\footnotetext{
${ }^{9}$ Disponível em:

<http://mareonline.com.br/wpcontent/uploads/2019/05/

Censo_Empreendimentos_24_julho.pdf >. Acesso em: 16 jul. 2020.
} 
tos ou pardos. O perfil étnico-racial varia também de acordo com as favelas. Nova Holanda apresenta maior concentração de pessoas autodeclaradas pretas, enquanto o Morro do Timbau apresenta maior número de pessoas brancas, em comparação com as outras favelas. A maioria das pessoas que mora na Maré, $61,8 \%$, afirma que vive no local desde que nasceu, no entanto, a presença nordestina é considerável. O Censo Maré (2013) aponta que 35.884, quase 26\% do total de moradores nasceram no Nordeste, nos estados de Paraíba e Ceará. Essa população, de maneira geral, apresenta-se em condições sócio-profissionais subalternizadas em comparação com as dos demais espaços da cidade.

Se tratarmos da renda total das pessoas que lá vivem, identificamos que esta é 49\% menor do que nos demais bairros da cidade - considerando pessoas de mesma escolaridade, idade e "raça", segundo estudo divulgado recentemente. $^{10}$

A luta pela educação é histórica entre os moradores da Maré, fato que resultou na ampliação substancial do número de escolas públicas nos últimos anos. O número de escolas passou de 22 unidades municipais em 2013 para 44 em 2018. No que concerne à infraestrutura educacional, estão instaladas na Maré 51 unidades educacionais, sendo 7 creches, 14 Espaços de Desenvolvimento Infantil (EDI), 1 Centro de Educação de Jovens e Adultos (CEJA), 24 unidades escolares de Ensino Fundamental e 5 unidades da rede estadual que oferecem o Ensino Médio.

Apesar dos avanços estruturais, a baixa escolaridade também é uma característica importante. O Censo informa que 30\% dos moradores da Maré frequentam a escola e destaca o quadro crônico de evasão escolar no período da adolescência, pois 19,6\% dos adolescentes entre 15 e 17 anos não frequentam a escola. No entanto, na faixa etária de 6 a 14 anos, a Maré tem uma taxa de 2\% de crianças fora da escola, número inferior à média verificada no município, em 2010 pelo censo, de 3,1\%. O percentual das pessoas não alfabetizadas na Maré é de 6\% entre pessoas com 15 anos ou mais, o que equivale a mais que o dobro da taxa de analfabetismo na cidade do Rio de Janeiro, de 2,8\%. O Censo Maré doi rezliado em 2013 e a publicaçao utilizada conforme está na bilbiografia, é de 2019, pela instituição Redes da Maré , apontam que 18,6\% dos moradores completaram apenas o ensino fundamental e 18\% concluíram o ensino médio.

${ }^{10}$ Dados produzidos pela pesquisa coordenada pelo pesquisador Marceno Neri (FGV) sobre "Desigualdade e 'Favelas Cariocas"”, Disponível em:

$<$ https://veja.abril.com.br/politica/desigualdade-o-rio-na-contramao-do-brasil/>. Acesso em: 16 jul. 2020. 
Enquanto $8 \%$ nunca frequentaram a escola, apenas $0,93 \%$ terminou a graduação e $0,03 \%$ o mestrado ou doutorado. Do total, $53,47 \%$ dos moradores da Maré não chegaram a completar o ensino fundamental.

A ausência de políticas públicas de qualidade atravessa o cotidiano da população. A maioria dos domicílios da Maré é destituída de legalização fundiária, ou seja, não há escritura dos imóveis em face da ocupação do local. Algumas construções, como o Conjunto Nova Maré, por exemplo, foram construídas sem laje, piso e com materiais de baixa qualidade. Entretanto, esse mesmo conjunto habitacional, segundo Silva e Barbosa (2005), recebeu uma premiação internacional pelo arrojo estético de sua forma arquitetônica inspirado nas construções de Paris, na França. Destaca-se também o fato de que famílias ainda residem em moradias confeccionadas de papelão e madeira, muito comuns nas recentes construções à beira da Av. Brasil e na comunidade de Marcílio Dias, o que faz lembrar as palafitas existentes até bem pouco tempo atrás. Nessas moradias é muito frequente a convivência com ratos, a ausência de saneamento básico e as dificuldades de acesso aos equipamentos públicos de saúde, educação e transporte. Outro elemento importante é que $0,3 \%$ ainda não têm água canalizada e, quanto à coleta de lixo, em $26,4 \%$ das casas os moradores levam o lixo até um local de coleta e em $71,5 \%$ dos domicílios, nos quais o lixo é coletado na porta, ${ }^{11}$ a frequência é limitada durante a semana.

Um dado importante são as mudanças constantes de endereço que são frequentes por vários motivos, destacando-se: as dificuldades socioeconômicas, que fazem as famílias migrarem de um estado para outro, a exemplo da considerável população nordestina; o aumento sensível do preço do aluguel; e a guerra do tráfico produzida pelos grupos civis armados e a ação ostensiva da polícia. A questão da violência, da repressão, contribui para a construção de uma imagem exclusivamente violenta sobre a favela. A ideia se acentua pela forma como a mídia a retrata, que criminaliza os moradores. Entretanto, a violência que o Estado imprime nesses territórios, ao não garantir políticas públicas de qualidade, como em outros espaços da cidade, é muito expressiva. Há em curso um verdadeiro genocídio ao povo pobre, negro e favelado que é a expressão da forma como o Estado desenvolve as políticas públicas nesses territórios.

11 Para mais informações ver: <https://www.redesdamare.org.br/br/info/12/censo-mare $>$. Acesso em: 16 jul. 2020. 


\section{Violência do Estado: a insegurança pública}

O tema da violência letal, como um problema de segurança pública, no caso particular do Brasil, começa a ser debatido no campo das ciências humanas e sociais em meados dos anos 1980, junto ao processo de redemocratização do país (MISSE, 2006; SOARES, 2003; ZALUAR, 2007). O crescimento da violência nesse período da redemocratização, além de se relacionar com a inflação e o desemprego, relaciona-se também, segundo Caldeira (2000, p. 56), “[...] com a falência do sistema judiciário, a privatização da Justiça, os abusos da polícia, a fortificação das cidades e a destruição dos espaços públicos". Nessa mesma linha, Adorno (2002) mostra que, além da violência no Brasil se constituir como um fenômeno determinado sócio-historicamente, ela está também associada à crise do sistema de segurança pública, ao acirramento das desigualdades sociais e à fragilização das políticas públicas dos direitos da cidadania implementadas nas décadas de 1980 e $1990 .^{12}$

Por outro ângulo, (ZALUAR, 2004) demonstra, através de dados empíricos, que durante o processo de redemocratização houve no Brasil uma mudança na "[...] organização transnacional do crime que afetou principalmente as regiões metropolitanas e, nelas, os bairros populares e as favelas" (ZALUAR, 2004, p. 210). Segundo Magaloni, Beatriz, Franco e Melo (2018), a ineficiência da atuação do Estado, no que tange à garantia do direito à segurança pública nas favelas e espaços populares, está correlacionada ao surgimento da organização e fortalecimento dos grupos armados que comercializam drogas ilícitas em varejo e estabelecem formas de regulação do espaço público e da ordem social. $\mathrm{Na}$ avaliação da autora, na medida em que o Estado percebe os grupos armados como uma real ameaça, declara uma "guerra contra o crime", que se reverbera em guerra contra os territórios e aqueles que o habitam.

Soares e Guindani (2007), ao se debruçarem sobre as respostas seletivas do Estado e da sociedade às manifestações da violência criminal, no Brasil contemporâneo, indicam a necessidade de se compreender o processo que muitos

\footnotetext{
${ }^{12}$ As pesquisas indicam que um conjunto de fatores pode ter contribuído para o crescimento dos índices da violência letal, entre o período de 1980 a 2000, quando apresenta crescimento em outras modalidades de crimes violentos, sobretudo aqueles potencializados pela política de guerra às drogas, ampliando e diversificando o grupo de pessoas envolvidas nas políticas criminais seletivas e racistas. Segundo a literatura, o que caracteriza o contexto dos anos 1990-2000 é uma intensificação do fenômeno em áreas urbanas e de forma explícita, em plena vigência do regime democrático, e a formação de organizações criminosas (SOARES; GUINDANI, 2007).
} 
autores designaram como "via autoritária de desenvolvimento do capitalismo"13 no país, o qual nos legou a tradição do pacto das elites e das transições negociadas, cuja contrapartida sempre foi a pauperização, de acentuado recorte de gênero e raça, das classes subalternas. Dito de outra forma, a criminalidade violenta, como expressão da violência estrutural, se mostra intrínseca ao processo de formação do racismo e patriarcado na sociedade brasileira, estando presente nas lógicas autoritárias e na imposição cultural desde os tempos da colonização até os dias atuais (GUIMARÃES, 2004). Há uma explícita e histórica expectativa de mais ordem e mais controle social sobre pobres, negros, indesejados das favelas e periferias, por intermédio do policiamento ostensivo, entendido como sinônimo de segurança pública. Essa demanda sensibiliza os órgãos de imprensa e as instituições que compõem o sistema de justiça e segurança, as quais se veem pressionadas a atender ao clamor da elite brasileira.

Nessa ótica, é importante assinalar, no presente artigo, o quanto os sistemas de políticas criminais ${ }^{14}$ no Brasil vêm reproduzindo os vieses conservadores e autoritários do Estado autocrático, onipresente na formação social e política do país. Verifica-se que uma vertente ideológica dominante, em nome da "Segurança Pública" e muito distante da lógica democrática que orienta princípios e diretrizes das demais políticas públicas ${ }^{15}$ no campo da Seguridade Social, induz a (e se reproduz na) perseguição de "jovens negros perigosos" e no combate bélico a territórios ("favelas de risco") que, supostamente, ameaçam a ordem instituída. Dito de outra forma, a frágil democracia em vigor no Brasil, após a Constituição de 1988, ainda não foi experimentada pelos moradores de favelas. Nesse território, a violência física e simbólica e as violações de direitos

13 Os autores indicam listagem de teóricos sobre o tema: Carlos Nelson Coutinho, José Paulo Netto, Florestan Fernandes, Otavio Guilherme Velho, Luiz Jorge Werneck Vianna, Simon Schwartzman, Raymundo Faoro. Destacam que a terminologia era mais variada que a substância semântica do conceito e oscilava de acordo com a filiação teórico-política que o autor privilegiasse. Destacam, ainda, que outros estudiosos da cultura interpretaram o modelo histórico destacando os fenômenos da "ambivalência" e do "sincretismo", por ângulos distintos e às vezes opostos: Sergio Buarque de Holanda, Gilberto Freyre, Roberto Schwartz, Roberto Da Matta, Luis Roberto Cardoso de Oliveira, Ricardo Benzaquem de Araújo, Kant de Lima, entre outros (SOARES; GUINDANI, 2007).

14 Os sistemas da política criminal, segundo Delmas-Marty, Mirelle (1992), envolvem as políticas penais e extrapenais de prevenção da criminalidade, as políticas da segurança pública, do sistema penitenciário e do sistema socioeducativo (GUINDANI, 2015).

$15 \mathrm{O}$ processo de reconstrução da nossa incipiente democracia brasileira, em curso desde o final da década de 1980, vem se caracterizando por incongruências, especialmente em relação à lógica democrática que norteou outras políticas públicas, sobretudo nas áreas de saúde e assistência social, como são os casos do Sistema Único de Saúde e do Sistema Único de Assistência Social (idem). 
fundamentais, praticadas cotidianamente por agentes da segurança pública, ainda se apresentam como regra.

Para Soares (2006), a política de segurança pública, de um modo geral, é ineficiente na prevenção e na repressão qualificada, na investigação e na conquista da indispensável confiança da população. As polícias não têm práticas de avaliação e planejamento e espaços de diálogo com a sociedade civil que possam criar diagnósticos sobre os problemas da violência e formas eficazes de enfrentá-los. $\mathrm{O}$ autor analisa a polícia como “[...] máquinas reativas, inerciais e fragmentárias, inscritas num ambiente institucional desarticulado e inorgânico, regido por marcos legais rígidos e inadequados" (SOARES, 2006, p. 100). A par disso, as instituições da segurança pública ainda apresentaram significativas resistências $^{16}$ à assimilação dos novos padrões e valores dos Direitos Humanos e do Estado Democrático ${ }^{17}$ de Direito, como veremos a seguir no caso das polícias fluminenses.

\section{Violência policial e armada no conjunto de favelas da Maré}

O território que compõe as 16 favelas da Maré é um dos espaços da cidade onde se reproduz o racismo estrutural e institucional (ALMEIDA, 2018) através da violência armada que impacta diretamente na vida da população. Mesmo com todos os equipamentos sociais e o significativo processo de lutas, os moradores da Maré experimentam há mais de três décadas uma situação de extrema instabilidade frente à violência urbana. Grupos armados vinculados ao tráfico internacional de drogas e armas passaram a exercer controle territorial e a regular as relações sociais em diversas comunidades na Maré. Ainda no final dos anos 1990, grupos de milicianos também se fizeram presentes em algumas comunidades, exercendo o papel de controladores de determinadas atividades ilícitas, tais como o transporte irregular e os serviços de segurança para os comerciantes da região.

\footnotetext{
${ }^{16}$ Ver análise sobre resistências à implantação do Sistema Único de Segurança Pública (SUSP) em Soares (2006).

17 A defesa dos direitos humanos, dentre eles a liberdade humana (integridade física dos cidadãos), os direitos políticos e as liberdades civis, é um dos indicadores mais utilizados para medir o nível de uma democracia. Esses direitos relacionam-se, principalmente, à administração do acesso à Justiça, com igualdade perante a lei, o acesso a um poder judicial imparcial e independente, proteção contra detenções arbitrárias e tortura, mecanismos de controle contra a corrupção, etc (AZEVEDO, 2005).
} 
O Estado, por sua vez, não se apresenta através de políticas públicas eficazes que possam romper com o ciclo da violência nesse território. A política de "guerra às drogas" incorporou o processo de militarização das ações policiais na Maré e, com isso, desenvolveu uma série de violações de direitos dos moradores, que sofrem constantemente com as intervenções policiais e demais confrontos armados onde vivem e que os paralisam nas suas atividades cotidianas.

Sob o argumento do enfrentamento aos grupos armados que atuam na região, o Estado atua a partir de uma série de violações de direitos, desde a paralisação de serviços públicos até as violações de direitos individuais, por meio das invasões de domicílio, ameaças, agressões físicas, verbais e psicológicas, entre outras. A lógica de atuação da política de segurança pública caracteriza-se por ações pontuais, através de operações policiais marcadas por intensos confrontos armados. As ações policiais costumam acontecer em horário de entrada e saída das escolas, onde muitas crianças e adolescentes transitam pelas ruas e correm risco de vida, afetando o acesso ao direito à saúde e educação.

Os dados do Instituto de Segurança Pública do estado do Rio de Janeiro (ISP, 2020) indicam uma tendência no estado de queda da letalidade violenta, nos últimos anos. As mortes violentas que contabilizaram 6.714 casos em 2018, diminuíram para 5.964 (11\%), em 2019. Entretanto, no mesmo período houve um aumento de $18 \%$ das mortes por intervenção de profissionais da segurança, em determinadas regiões da cidade, como o bairro Maré. Na cidade ocorreram 1.810 mortes cometidas por intervenção policial, contra 1.534, em 2018. Essa prática de atuação das polícias no Rio de Janeiro impacta, nesse sentido, diretamente na violação de direitos fundamentais da população pobre, negra e favelada, sobretudo o direito à vida e ao acesso à justiça.

De acordo com informações extraídas do Boletim Direito à Segurança Pública na Maré, que expõe os dados da violência armada em números, "[...] entre 2016 e 2019 foram contabilizadas 132 vítimas letais, 121 pessoas feridas por armas de fogo [...]" (REDES DA MARÉ, 2020, p. 8) decorrente de operações policiais, no conjunto de favelas da Maré.

Em 2018 foram realizadas 16 operações policiais que resultaram no total em 19 pessoas mortas, 10 pessoas feridas, 10 dias de fechamento das escolas e 11 dos postos de saúde (REDES DA MARÉ, 2019, p.3). Das 19 mortes por intervenção de agentes do Estado (índice ISP), apenas três tiveram perícias realizadas. Nesse ano, a taxa desse tipo de morte na Maré foi de 13,7 por 100 mil habitantes, enquanto a taxa do estado e do município são, respectivamente, 9,0 
e 8,4 (REDES DA MARÉ, 2019, p. 8). Das 16 operações, nenhuma foi realizada em Roquete Pinto e Praia de Ramos que são controladas por grupos paramilitares (REDES DA MARÉ, 2019, p. 5). Foram 27 confrontos entre grupos armados que contabilizaram ao todo 5 pessoas mortas e 7 feridas, porém não causaram impacto no funcionamento das escolas e dos postos de saúde (REDES DA MARÉ, 2019, p. 3). Além disso, 41 pessoas relataram violações de direitos a Redes da Maré, sendo que 15 pessoas relataram violência verbal/psicológica/ameaça, 12, violência física/tortura, e 8 , cárcere privado, entre outros tipos de violações (REDES DA MARÉ, 2019, p. 7). As pessoas do sexo masculino representam $96 \%$ das vítimas, $79 \%$ são negras, e $72 \%$ têm idade entre 13 e 29 anos. As vidas de crianças, inclusive, têm sido ceifadas por agentes do Estado (REDES DA MARÉ, 2019, p. 9).

Em 2019, foram realizadas 39 operações policiais, 13 com uso de helicóptero, que resultaram no total de 34 pessoas mortas (maior número desde 2016) e 30 feridas por armas de fogo, além de terem impactado no fechamento das escolas (24 dias) (REDES DA MARÉ, 2019, p. 6) e Unidades Básicas de Saúde (25 dias), com impacto em 15.000 atendimentos que deixaram de ser realizados (REDES DA MARÉ, 2019, p. 7). O aumento das operações policiais e da letalidade dessas está representado na taxa de mortes por intervenção de agentes do Estado, que em 2019 foi de 23,4/100.000 habitantes, enquanto no estado a taxa foi de 10,5 e no município de 10,9 para cada 100.000 habitantes (REDES DA MARÉ, 2019, p. 19). Nesse ano também foram registradas 20 ações entre grupos armados que totalizaram 15 pessoas mortas, 15 feridas e 117 dias de tiroteios em diferentes favelas da Maré (REDES DA MARÉ, 2019, p. $5)$.

Os relatos de violações de direitos foram maiores em 2019, sendo 30 provocadas pelos grupos armados e 110 por agentes do Estado, totalizando 140 denúncias. Dessas 110, 89 pessoas relataram que as violações foram cometidas por agentes da Polícia Militar e 21 da Polícia Civil (REDES DA MARÉ, 2019, p. 14). Alvo preferencial dessas violações de direito por agentes do Estado, 58\% das vítimas são mulheres (REDES DA MARÉ, 2019, p. 15).

Os grupos mais atingidos se repetiram como no ano de 2018. As pessoas do sexo masculino representam $94 \%$ das vítimas, $96 \%$ são negras, e $85 \%$ têm idade entre 15 e 29 anos. Um dado muito significativo em 2019 é que 100\% das pessoas mortas em operações policiais eram pretas ou pardas, escancarando o racismo institucional impregnado na política de segurança pública. 
Segundo a $8^{a}$ edição do "Boletim De Olho no Corona!", produzido pela Redes da Maré, no primeiro semestre de 2020 ocorreram 11 operações policiais que resultaram em 12 pessoas feridas e 4 pessoas assassinadas. O boletim chama atenção para o fato dessas ações terem se tornado ainda mais prejudiciais com o início de pandemia, trazendo impactos mais complexos, pois limitam a mobilidade dos moradores pelo território, interrompem o atendimento das unidades de saúde, causam pânico e afetam a saúde mental e emocional dos moradores.

A partir do cenário de violações de direitos instaurado por conta da pandemia do novo coronavírus, moradores de favelas, coletivos, organizações e movimentos sociais solicitaram a suspensão das operações policiais. O ministro Edson Fachin, do Supremo Tribunal Federal, no dia 6 de junho, em decisão liminar, determinou a suspensão da realização de operações policiais em favelas do Rio de Janeiro durante o período de pandemia, salvo em casos de excepcionalidade. De acordo com o ministro, nesses casos, deverão ser adotados cuidados para não colocar em risco ainda maior a população, a prestação de serviços públicos sanitários e o desempenho de atividades de ajuda humanitária realizadas por moradores e organizações que atuam nesses territórios.

Quando se compara os impactos da violência armada no período de isolamento social, entre 16/03 e 20/06 deste ano, com o mesmo período de 2019, segundo pesquisa da Redes da Maré, as operações policiais reduziram de 16 para 4 e, por consequência, o número de mortes em decorrência dessas ações caíram de 15 para 1, o número de feridos por arma de fogo reduziu de 19 para 7, e os dias sem atendimento nas unidades de saúde caíram de 9 para 3. Nesse sentido, ao comparar os dois períodos, estima-se que 14 vidas foram salvas (REDES DA MARÉ, 2020).

\section{O direito à vida em meio à "necropolítica"}

No dia 6 de maio de 2019 ocorreu uma operação policial de grande porte no Conjunto Esperança, uma das favelas da Maré. Nessa ocasião, um helicóptero, juntamente com dois carros blindados, encurralou quatro pessoas vinculadas a um grupo criminoso, que entraram na casa de um morador. Nessa casa, ao serem confrontados pela polícia, os jovens jogaram as armas no chão e se renderam com a mão para cima. Mesmo agindo dessa maneira foram executados pelos policiais na presença dos moradores. Seus corpos foram arrastados 
do terceiro andar da casa e colocados dentro do blindado. Logo em seguida, nessa mesma operação, foram registradas as mortes de mais quatro pessoas, na mesma rua onde aconteceram os quatro homicídios anteriores. Ou seja, em apenas um dia, em uma rua, oito jovens, na maioria negros, foram sumariamente assassinados por agentes que deveriam resguardar seus direitos (REDES DA MARÉ, 2019).

O fato narrado exemplifica a farsa dos direitos constitucionais e escancara a ilegalidade do Estado. A democracia no Brasil é geograficamente e racialmente desigual, e no que tange à política de segurança pública essa desigualdade é potencializada. O relato demonstra, entre outras violações de direitos, um desprezo ao direito à vida e à perícia, sem constrangimentos por parte dos agentes. Apesar de o Estado executar as operações policiais nos territórios de favela à margem da legislação, a verdade é que essas ações acabam por representar a normalidade. Não se encaixa na jurisprudência, mas sua prática cotidiana faz com que se instituam como um modelo de segurança pública.

O poder político estatal se apropria da morte como objeto de gestão pública. Uma gestão chamada por Mbembe (2018) de "necroplítica", que está essencialmente ligada a opressões estruturais de raça, classe e gênero. O controle da vida nas mãos do Estado se caracteriza não apenas na morte em si, mas também por gerar condições que a favoreçam. Dessa forma, o Estado decide quem morre, como morre e em que condições se morre.

A "necropolítica" é direcionada principalmente para favelas e espaços populares, onde o Estado Democrático não prioriza a vida da população, mas sim o seu extermínio. As operações policiais têm utilizado a força como o primeiro e praticamente único instrumento de intervenção nas favelas. Intervenções essas caracterizadas pela desqualificação, inconsequência e ilegalidade da ação que impactam negativamente a vida dos moradores e não garante o direito à segurança pública, pelo contrário, aparecem como principal instrumento de violação de direitos.

\section{Reflexões conclusivas}

As cidades brasileiras são hoje a expressão urbana de uma sociedade que nunca conseguiu superar sua herança colonial para construir uma sociedade que distribuísse de forma menos desigual suas riquezas. Sua construção foi marcada pela concentração de terra, renda e poder, pelo exercício do coronelismo, 
política do favor e pela aplicação arbitrária da lei. Com a intensidade da urbanização, espaços diferenciados são produzidos, identificando seus moradores de maneira distinta, sendo divididos entre centro e periferia.

A segregação socioespacial é uma das principais marcas da desigualdade racial engendrada nas cidades brasileiras desenvolvidas em um contexto específico de capitalismo periférico. A gestão das políticas públicas pelo Estado nas regiões segregadas da cidade, como favelas e espaços populares, pauta-se pela ilegalidade das ações e tem a violência como principal elemento.

A partir dos dados da violência armada na Maré, percebe-se que a vida das quase 140 mil pessoas que moram na Maré, especialmente jovens negros, não está resguardada, na prática, por nenhum dispositivo constitucional. É urgente a construção de mecanismos que garantam os direitos coletivos e individuais dos moradores da Maré e demais favelas do Rio de Janeiro. Mecanismos que ampliem formas de acesso à justiça, espaços democráticos e de participação social e colaborem para a redução da violência policial em territórios de favelas e periferias.

Dentro dos limites da democracia burguesa é possível um modelo de polícia que preze pela redução de danos e do racismo institucional, desde que passe a centrar sua função na garantia dos direitos fundamentais de todas e todos os cidadãos e na integração com as pessoas. Uma polícia altamente preparada para compreender a sociedade como um ambiente conflitivo no qual o problema da violência e da criminalidade é complexo, por isso a segurança pública deve perpassar o âmbito social e cultural. Assim sendo, a democracia exige uma atuação da polícia que não se restrinja à função de garantir a ordem pública sustentada apenas em ações repressivas, mas essencialmente com a função protetora do cidadão em ambiente de conflito.

Construir mecanismos eficientes de redução da violência policial; priorizar a prevenção e a investigação dos crimes contra a vida; atuar no controle de armas de fogo, diminuindo sua disponibilidade; criar programas de prevenção social da violência; pensar o desencarceramento e adotar políticas de drogas que protejam os que são atingidos pela violência sistêmica são medidas essenciais para pensar um modelo de segurança pública que priorize a vida. Essas medidas devem ser acompanhadas do controle social e da transparência das informações. Interromper a tragédia dos crimes contra a vida é condição necessária para a construção de uma sociedade democrática. 


\section{Referências}

ADORNO, S. Crime e violência na sociedade brasileira contemporânea. Jornal de Psicologia-PSI, n. 132 , p. 7-8, abr./jun. 2002.

ALMEIDA, S. L. de. O que é racismo estrutural? Belo Horizonte: Letramento, 2018.

ANDERSON, P. Balanço do Neoliberalismo In: SADER, E; GENTILI, P. Pós-Neoliberalismo - As políticas Sociais e o Estado Democrático. Rio de Janeiro, Editora: Paz e Terra, 2005.

AZEVEDO, R. A Criminalidade e justiça penal na América Latina. Sociologias, Porto Alegre, ano 7, n. 13, p. 212-241, jan./jun. 2005.

CALDEIRA, T. P. Cidade de Muros: Crime, Segregação e Cidadania em São Paulo. São Paulo: Editora 34/Edusp, 2000.

CAMPOS, A. Do Quilombo à Favela - a produção do "Espaço Criminalizado" no Rio de Janeiro. Rio de Janeiro: Editora Bertrand Brasil, 2004.

CORRÊA, R. L. O Espaço Urbano. São Paulo: Editora Ática, 1995.

FACEIRA, L.; FARIAS, F. (Org.). Punição e Prisão: ensaios críticos. 1. ed. Rio de Janeiro: Lumen Juris, 2015.

FERNANDES, F. Capitalismo dependente e classes sociais na América Latina. Rio de Janeiro: Editora Zahar, 1981.

GRAMSCI, A. Maquiavel - notas sobre o Estado e a Política - Cadernos do Cárcere volume 03. Rio de Janeiro: Editora Civilização Brasileira, 2000.

GUimarãeS, A. S. A. Preconceito de cor e racismo no Brasil. Rev. Antropol., São Paulo, v. 47, n. 1, p. 9-43, 2004.

GUINDANI, M. K. A expresão da violência no sistema prisional brasileiro In: Punição e Prisão: ensaios criticos.1 ed.Rio de Janeiro: Lumen Juris, 2015, v.1, p. 45-62.

HAESBAERT, R. Concepções de territórios para entender a desterritorialização. In: Milton Santos...[et.al.] Território - territórios. Rio de Janeiro, Editora Lamparina, 2007.

HARVEY, D. Espaços de Esperança. São Paulo: Editora Loyola, 2004. O Neoliberalismo: história e implicações. São Paulo: Editora Loyola, 2008. 
IAMAMOTO, M.V. Serviço Social em tempo de Capital Fetiche- Capital financeiro, trabalho e questão social. São Paulo: Editora Cortez, 2007.

IANNI, O. Pensamento Social no Brasil. São Paulo: Editora EDUSC, 2004. ISP. Segurança Pública em números 2019: Evolução dos principais indicadores de criminalidade e atividade policial no estado do Rio de Janeiro de 2003 a 2019. Rio de Janeiro, Instituto de Segurança Pública, 2020. Disponivel: http://arquivos.proderj.rj.gov.br/isp_imagens/Uploads/SegurancaemNumeros2019.pdf. Acessado em 15 de jul de 2020.

LEFEBVRE, H. A revolução urbana. Belo Horizonte: Editora UFMG, 2008. LENIN, V. I. O imperialismo: Fase superior do capitalismo. São Paulo: Editora Centauro, 2005.

MAGALONI, B.; MELO, V.; SILVA, E.S.; SILVA, J. S. Percepção de moradores sobre Segurança Pública e os dilemas das Unidades de Polícia Pacificadora em favelas do Rio de Janeiro. 2018. Disponível em: < http://redesdamare.org.br/media/livros/Relatorio-Sobre-Seguranca-Publica-e-Dilemas-daUPP.pdf>. Acesso em: 15 jul. 2020.

MARICATO, E. Brasil, Cidades alternativas para a crise urbana. Petrópolis: Editora Vozes, 2008.

MBEMBE, A. Necropolítica: Biopoder, soberania, estado de exceção, política da morte. São Paulo, Editora n-1, 2018.

MISSE, M. Crime e violência no Brasil contemporâneo: estudos de sociologia do crime e da violência urbana. Rio de Janeiro: Lumen Juris, 2006.

MONIZ, E. Canudos: a guerra social. 2. ed. Rio de Janeiro: Editora Elo, 1987.

NETTO, J.P; BRAZ, M. Economia Política - uma introdução crítica. São Paulo: Editora Cortez, 2006.

REDE OBSERVATÓRIO DA SEGURANÇA PÚBLICA RIO DE JANEIRO. 2019. REDEOBS_infografico. No 01, julho de 2019 Disponível em: $<$ https://www.ucamcesec.com.br/wp-content/uploads/2019/07/REDEOBS_infografico_01_julho_final.pdf $>$. Acesso em: 15 jul. 2020.

REDES DA MARÉ. CENSO Maré 2019. Disponível em: < https://www.redesdamare.org.br/media/downloads/arquivos/

CensoMare_WEB_04MAI.pdf>. Acesso em: 15 jul. 2020. 
Boletim Direito A Segurança Pública. 2016. Disponível em:

$<$ https://www.redesdamare.org.br/media/downloads/arquivos/BoletimSegPublica.pdf>. Acesso em: 15 jul. 2020.

Boletim Direito A Segurança Pública. 2017. Disponível em:

$<$ https://www.redesdamare.org.br/media/downloads/arquivos/BoletimSegPublica_2017.pdf>. Acesso em: 15 jul. 2020.

Boletim Direito A Segurança Pública. 2018. Disponível em:

$<$ https://www.redesdamare.org.br/media/downloads/arquivos/BoletimSegPublica2018.final.pdf>. Acesso em: 15 jul. 2020.

Boletim Direito A Segurança Pública. 2019. Disponível em:

$<$ https://www.redesdamare.org.br/media/downloads/arquivos/BoletimSegPublica_2019.pdf>. Acesso em: 15 jul. 2020.

Boletim De Olho no Corona. 8. ed. 2020. Disponível em:

$<$ https://www.redesdamare.org.br/media/downloads/arquivos/06E08-BoletimDeOlho.pdf>. Acesso em: 15 jul. 2020.

SANTOS, M. Por uma outra globalização: do pensamento único à consciência universal. Rio de Janeiro: Editora Record, 2008.

. O Espaço do Cidadão. São Paulo: Editora Edusp, 2007.

SILVA, J.S e; BARBOSA, J.L. Favela - alegria e dor na cidade. Rio de Janeiro: Editora $[\mathrm{X}]$ Brasil, 2005.

SOARES, L. E. Novas Políticas de Segurança Pública. Estudos Avançados, v. 17, n. 47, p. 75-96, São Paulo, 2003. Disponível em: < https://www.scielo.br/ scielo.php?script $=$ sci_arttext\&pid $=$ S0103-40142003000100005 >. Acesso em: 15 jul. 2020.

Legalidade libertária. Rio de Janeiro: Editora Lumen, 2006.

SOARES, L. E.; GUINDANI, M. K. A. La Tragedia brasilena la violencia estatal y social y las politicas de seguridad necesaria. Nueva Sociedad, no 208 v. 01, p. 56-72, Argentina, março/abril de 2007. Disponível em: < https:// nuso.org/articulo/la-violencia-estatal-y-social-y-las-politicas-de-seguridadnecesarias/ >. Acessado em: 15 jul de 2020.

TROTSKY, L. A Revolução Permanente. São Paulo: Editora Expressão Popular, 2007.

VALLADARES, L. do P. A invenção da favela: do mito de origem a favela.com. Rio de Janeiro: FGV, 2005. 


\section{VALLA, V. V., ALGEBAILE, E. e GUIMARÃES, M. B. Classes populares}

no Brasil: exercício de compreensão. Rio de Janeiro: Escola Nacional de Saúde Pública Sergio Arouca - ENSP, 2001.

ZALUAR, A. Integração perversa: pobreza e tráfico de drogas. Rio de Janeiro: Editora da FGV, 2004.

Democratização inacabada: fracasso da segurança pública. Estudos Avançados, v. 21, n. 61, p. 31-49, São Paulo, 2007. Disponível em: <https:// www.scielo.br/pdf/ea/v21n61/a03v2161>. Acessado em: 15 de jul de 2020. 